\title{
Optimal Response to a Transitory Demographic Shock in Social Security Financing
}

\author{
Juan C. Conesa and Carlos Garriga
}

\begin{abstract}
The authors consider a transitory demographic shock that affects negatively the financing of retirement pensions-that is, workers either would have to pay more or retirees would receive less. In contrast to the existing literature, the authors endogenously determine optimal policies rather than explore the implications of exogenous parametric responses. Their approach identifies optimal strategies of the Social Security Administration to guarantee the financial sustainability of existing retirement pensions in a Pareto-improving way. Hence, no cohort will pay the cost of the demographic shock. The authors find that the optimal strategy is based on the following ingredients: elimination of compulsory retirement, a change in the structure of labor income taxation, and a temporary increase in the level of government debt. (JEL D58, D91, H55)
\end{abstract}

Federal Reserve Bank of St. Louis Review, January/February 2009, 91(1), pp. 33-48.

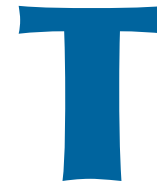

he financial sustainability of the Social Security system is an important policy concern due to the aging of the U.S. population and in particular of the baby-boom generation. According to estimates of the Social Security Administration, the dependency ratio (measured as population age 65 or older over population between ages 20 and 64) will increase from its present 21 percent to 27 percent in the year 2020, 37 percent in 2050, and 42 percent in 2080 under the scenario they call the medium population growth (Figure 1).

Under this demographic scenario, the Social Security system, which is a pay-as-you-go (PAYG) program, will face clear financial imbalances unless some reforms are introduced. In this paper, we explore the optimal response to a transitory demographic shock that affects negatively the financing of retirement pensions. ${ }^{1}$ In contrast to existing literature, we follow an approach that is similar to that used in Conesa and Garriga (2008) and endogenously determine optimal policies rather than exploring implications of exogenous parametric policies. Our approach determines the optimal strategy of the Social Security Administration to guarantee the financial sustainability of current retirement pensions in the least distortionary way. Moreover, no cohort will have to pay the welfare cost of the demographic shock.

Notice that we are concerned only about efficiency considerations in the financing of retirement pensions rather than about the efficiency of their existence in the first place. Their existence

1 In our artificial economy, we assume the transitory nature of the demographic shock for computational convenience, while Figure 1 clearly shows the permanent nature of the future demographic shock faced by the U.S. population structure.

\footnotetext{
Juan C. Conesa is an associate professor at the Universitat Autònoma de Barcelona. Carlos Garriga is an economist at the Federal Reserve Bank of St. Louis. The authors thank Mark Keightley, Georges de Ménil, Pierre Pestieau, and two anonymous referees for their very useful comments. Both authors acknowledge financial support from the Spanish Ministerio de Educación y Ciencia, SEJ2006-03879. Conesa also acknowledges support from the Barcelona Economics Program and Generalitat de Catalunya through 2005 SGR00447.

This article was originally published in Pension Strategies in Europe and the United States (Robert Fenge, Georges de Ménil, and Pierre Pestieau, editors), Cambridge, MA: MIT Press, pp. 98-113. Reprinted here with permission.

C 2009, MIT Press. The views expressed in this article are those of the author(s) and do not necessarily reflect the views of the Federal Reserve System, the Board of Governors, or the regional Federal Reserve Banks. Articles may be reprinted, reproduced, published, distributed, displayed, and transmitted in their entirety if copyright notice, author name(s), and full citation are included. Abstracts, synopses, and other derivative works may be made only with prior written permission of the Federal Reserve Bank of St. Louis.
} 


\section{Figure 1}

\section{Population Age 65 and Older Over Population Ages 20 to 64}

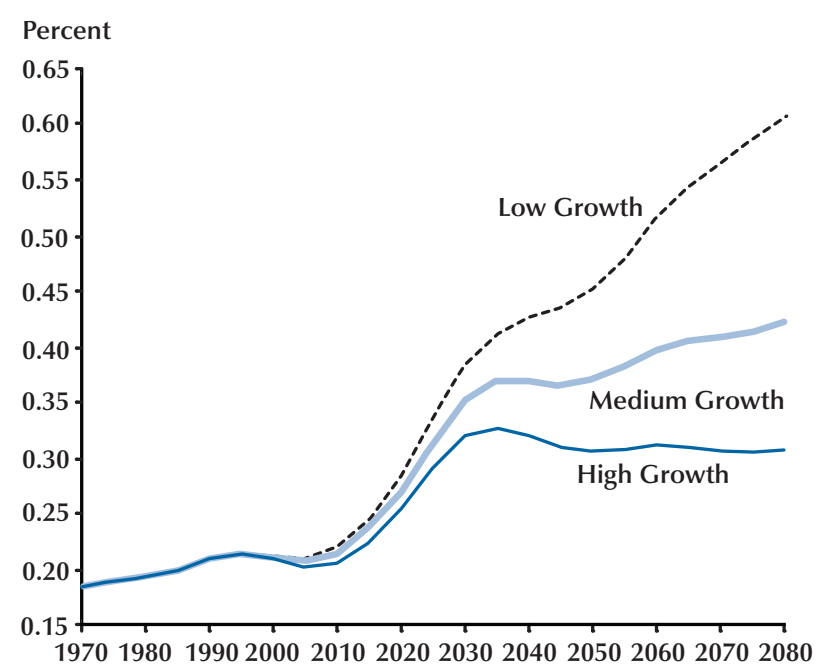

SOURCE: Social Security Administration.

might be justified on different grounds. ${ }^{2}$ We do not model why Social Security was implemented in the first place or why Social Security benefits are provided through a potentially inefficient tax system.

We consider for our experiments an unexpected transitory demographic shock, even though these shocks are certainly predictable by looking at Figure 1. If the demographic shock is predictable, the fiscal authority should have reacted to it in advance. However, we believe it is more interesting to focus on what should be done from now on rather than on what should have been done. In this sense, prediction of a demographic shock without action is equivalent to the shock being unexpected. However, the transitory nature of the shock considered is a limitation of the analysis driven by computational tractability.

\footnotetext{
2 One basic reason could be dynamic inefficiencies (see Diamond, 1965, or Gale, 1973). Also, even in a dynamically efficient economy, Social Security might be sustained because of political economy considerations (see Grossman and Helpman, 1998; Cooley and Soares, 1999; or Boldrin and Rustichini, 2000). Also, Social Security might be part of some general social contract, as in Boldrin and Montes (2005).
}

The quantitative evaluation of Social Security reforms has been widely analyzed in the literature. ${ }^{3}$ Demographic considerations play an important role in the Social Security debate, but there are few quantitative studies of policy responses to demographic shocks and none to our knowledge from an optimal fiscal policy perspective. In particular, De Nardi, Imrohoroglu, and Sargent (1999) consider the economic consequences of different alternative fiscal-adjustment packages to solve the future Social Security imbalances associated with the projected demographics in the United States. They find that all fiscal adjustments impose welfare losses on transitional generations. In particular, policies that partially reduce retirement benefits (by taxing benefits, postponing retirement, or taxing consumption), or that gradually phase benefits out without compensation yield welfare gains for future generations but make most of the current generations worse off. They conclude that a sustainable Social Security reform requires reducing distortions in labor supply or in consumption and saving choices and some transition policies to compensate current generations (issuing government debt). Our approach allows for the endogenous determination of such policies in a way that nobody faces welfare losses. In other words, everybody will be guaranteed the same level of welfare as in the benchmark economy without a demographic shock. However, for computational tractability we will substantially simplify the nature of the demographic shocks relative to De Nardi, Imrohoroglu, and Sargent (1999).

Jeske (2003) also analyzes payroll adjustments to demographic shocks in an economy similar to ours. He finds that in contrast with the benchmark economy not all cohorts are worse off due to the arrival of the baby boomers. The parents of the baby boomers gain about 0.5 percent of average lifetime consumption, the baby boomers lose 1 percent, the children of boomers gain 2 percent, and the grandchildren lose more than 2 percent. The intuition for this result comes from move-

\footnotetext{
3 Feldstein and Liebman (2001) summarize the discussion on transition to investment-based systems, analyzing the welfare effects and the risks associated with such systems.
} 
ments in factor prices implied by the demographic shock and the implied payroll taxes adjustment to balance the per-period government budget constraint.

In contrast to both of them, we do not analyze the different implications of exogenously specified strategies to guarantee sustainability but instead optimize over this policy response to demographic shocks following the Ramsey approach. The quantitative analysis of optimal fiscal policy in overlapping generations economies was pioneered by Escolano (1992) and has been recently considered by Erosa and Gervais (2002) and Garriga (1999). Conesa and Garriga (2008) used a similar framework to analyze the design of Social Security reforms, and therefore the focus was on efficiency considerations, abstracting from sustainability issues.

Our main conclusions indicate that the optimal strategy in absorbing a negative demographic shock consists of the following:

- Changing the age structure of labor-income taxation. In particular, labor-income taxes of the young should be substantially decreased.

- Eliminating compulsory retirement and allowing cohorts older than age 65 to supply labor in the market.

- Increasing the level of government debt during the duration of the demographic shock and then repaying it slowly.

We find that the welfare gains will be concentrated for generations born in the distant future after the demographic shock is over, while it does maintain the benchmark welfare level for existing cohorts and current newborns during the shock. Therefore, no generation is worse off along the fiscal-adjustment process implied by the demographic shock. This result contrasts with the findings of De Nardi, Imrohoroglu, and Sargent (1999), and Jeske (2003), where either current or future generations suffer important welfare losses. More important, we find that a sustainable Social Security reform does not necessarily require reducing distortions in consumption and saving choices. A reduction in labor supply distortions and the issuing of government debt are sufficient to compensate current generations.
In addition, we show that the welfare costs of distortionary taxation are quantitatively important right after the demographic shock but are relatively less important in the long run.

The distortionary impact of the financing of pensions in our artificial economy is assumed rather than endogenously determined. In our benchmark economy, pensions are financed through linear age-independent payroll taxes, and individuals do not establish a link between their individual contributions to the system and their future pensions. Hence, all the welfare gains obtained in our analysis are generated by the minimization of distortions and the redistribution of these additional resources. Indeed, it could not be otherwise since the possibility of Pareto improvements exists only because of the presence of distortions.

We also show that when the income from retirement pensions is not taxable, the government could use this fact to replicate lump-sum taxation and achieve first-best allocations. Yet since we want to focus on an environment where the government is restricted to distortionary taxation, we consider only an environment where the fiscal treatment of retirement pensions is constrained to be the same as that of regular labor income.

The rest of the paper describes the benchmark theoretical framework used, our method of parameterizing our benchmark economy, the optimal fiscal policy problem using the primal approach, the experiment we perform, the demographic shock, and our analysis of the optimal response.

\section{THE THEORETICAL ENVIRONMENT IN THE BENCHMARK ECONOMY}

\section{Households}

The economy is populated by a constant measure of households who live for $I$ periods. These households are forced to retire in period $i_{r}$. We denote by $\mu_{i, t}$ the measure of households of age $i$ in period $t$. Preferences of a household born in period $t$ depend on the stream of consumption and leisure this household will enjoy. Thus, the utility function is given by 


$$
U\left(c^{t}, I^{t}\right)=\sum_{i=1}^{I} \beta^{i-1} u\left(c_{i, t+i-1}, 1-l_{i, t+i-1}\right) .
$$

Every period, each household owns one unit of time that they can allocate to work or leisure. One unit of time devoted to work by a household of age $i$ translates into $\varepsilon_{i}$ efficiency units of labor in the market, and these are constant over time.

\section{Technology}

The production possibility frontier is given by an aggregate production function $Y_{t}=F\left(K_{t}, L_{t}\right)$, where $K_{t}$ denotes the capital stock at period $t$, and

$$
L_{t}=\sum_{i=1}^{I} \mu_{i, t} \varepsilon_{i} l_{i, t}
$$

is the aggregate labor endowment measured in efficiency units. We assume the function $F$ displays constant returns to scale, is monotonically increasing, is strictly concave, and satisfies the Inada conditions. The capital stock depreciates at a constant rate $\delta$.

\section{Government}

The government influences this economy through the Social Security and the general budget. For simplicity, we assume that initially (before the demographic shock) these two programs operate with different budgets. Pensions $\left(p_{t}\right)$ are financed through a payroll tax $\left(\tau_{t}^{p}\right)$, and the Social Security budget is balanced. On the other hand, the government collects consumption taxes $\left(\tau_{t}^{C}\right)$, labor income taxes $\left(\tau_{t}^{l}\right)$, and capital-income taxes $\left(\tau_{t}^{k}\right)$ and issues public debt $\left(b_{t}\right)$ to finance an exogenously given stream of government consumption $\left(g_{t}\right)$.

Thus, the Social Security and government budget constraints are respectively given by

$$
\tau_{t}^{p} w_{t} \sum_{i=1}^{i_{r}-1} \mu_{i} \varepsilon_{i} l_{i, t}=p_{t} \sum_{i=i_{r}}^{I} \mu_{i} \text {, and }
$$

$$
\begin{aligned}
& \tau_{t}^{c} \sum_{i=1}^{I} \mu_{i} c_{i, t}+\tau_{t}^{l}\left(1-\tau_{t}^{p}\right) w_{t} \sum_{i=1}^{i_{r}-1} \mu_{i} \varepsilon_{i} l_{i, t} \\
& +\tau_{t}^{k} r_{t} \sum_{i=1}^{I} \mu_{i} a_{i, t}+b_{t+1}=g_{t}+\left(1+r_{t}\right) b_{t} .
\end{aligned}
$$

In response to the demographic shock, however, both budgets are integrated, and we allow the government to transfer resources across budgets to finance the retirement pensions.

\section{Market Arrangements}

We assume there is a single representative firm that operates the aggregate technology, taking factor prices as given. Households sell an endogenously chosen fraction of their time as labor $\left(l_{i, t}\right)$ in exchange for a competitive wage of $w_{t}$ per efficiency unit of labor. They rent their assets $\left(a_{i, t}\right)$ to firms or the government in exchange for a competitive factor price $\left(r_{t}\right)$ and decide how much to consume and save out of their disposable income. The sequential budget constraint for a workingage household is given by

$$
\begin{aligned}
& \left(1+\tau_{t}^{c}\right) c_{i, t}+a_{i+1, t+1}=\left(1-\tau_{t}^{l}\right)\left(1-\tau_{t}^{p}\right) w_{t} \varepsilon_{i} l_{i, t} \\
& +\left(1+\left(1-\tau_{t}^{k}\right) r_{t}\right) a_{i, t}, \quad i=1, \ldots, i_{r}-1 .
\end{aligned}
$$

On retirement, households do not work and receive a pension in a lump-sum fashion. Their budget constraint is

$$
\begin{aligned}
& \left(1+\tau_{t}^{c}\right) c_{i, t}+a_{i+1, t+1}=\left(1-\tau_{t}^{l}\right) p_{t} \\
& +\left(1+\left(1-\tau_{t}^{k}\right) r_{t}\right) a_{i, t}, \quad i=i_{r}, \ldots, I .
\end{aligned}
$$

The alternative interpretation of a mandatory retirement rule is to consider different laborincome tax rates for individuals of ages above and below $i_{r}$. In particular, a confiscatory tax on labor income beyond age $i_{r}$ is equivalent to compulsory retirement. Both formulations yield the same results. However, when we study the optimal policy, we prefer this alternative interpretation since it considers compulsory retirement as just one more distortionary tax that the fiscal authority can optimize over.

In the benchmark economy, a market equilibrium is a sequence of prices and allocations such 
that consumers maximize utility (equation 1) subject to their corresponding budget constraints (equations (4) and (5)), given the equilibrium prices; firms maximize profits given prices; the government and the Social Security budgets are balanced (equations (2) and (3)); and markets clear and feasibility is satisfied.

\section{PARAMETERIZATION OF THE BENCHMARK ECONOMY}

\section{Demographics}

We choose one period in the model to be the equivalent of 5 years. Given our choice of period, we assume households live for 12 periods, so that the economically active life of a household starts at age 20, and we assume that households die with certainty at age 80 . In the benchmark economy, households retire in period 10 (equivalent to age 65 in years).

Finally, we assume that the mass of households in each period is the same. All these assumptions imply that in the initial steady state the dependency ratio is 0.33 rather than the 0.21 observed nowadays. The reason is that in our simple environment there is no lifetime uncertainty.

\section{Endowments}

The only endowment that households have is their efficiency units of labor at each period. These are taken from Hansen's (1993) estimates, conveniently extrapolated to the entire lifetime of households (Figure 2). ${ }^{4}$

\section{Government}

We assume that in the benchmark economy the government runs two completely independent budgets. One is a Social Security budget that operates on a balanced budget. The payroll tax is taken from the data and is equal to 10.5 percent, which is the Old-Age and Retirement Insurance (OASI).

\footnotetext{
4 To avoid sample selection biases, we assume that the rate of decrease of efficiency units of labor after age 65 is the same as in the previous period.
}

\section{Figure 2}

\section{Age Profile of Efficiency Units of Labor}

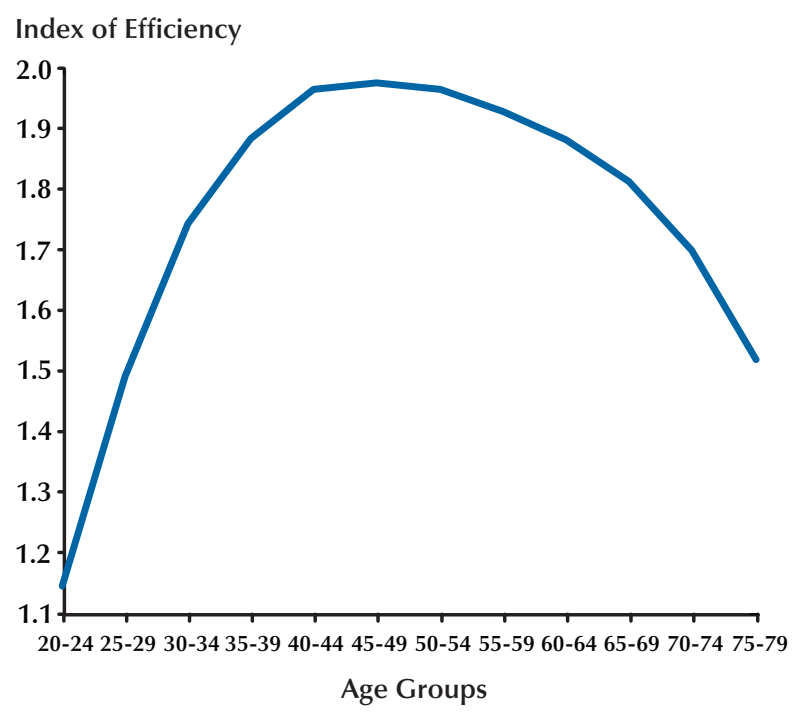

SOURCE: Hansen (1993).

We exclude a fraction going to disability insurance; the OASDI is 12.4 percent. Our assumptions about the demographics together with the balanced budget condition directly determine the amount of the public retirement pension. It will be 31.5 percent of the average gross labor income.

The level of government consumption is exogenously given. It is financed through a consumption tax, set equal to 5 percent, a marginal tax on capital income equal to 33 percent, and a marginal tax on labor income net of Social Security contributions equal to 16 percent. We have estimated these effective tax rates following Mendoza, Razin, and Tesar (1994). The effective distortion of the consumption-leisure margin is given by $\left(1-\tau^{1}\right)\left(1-\tau^{p}\right) /\left(1+\tau^{C}\right)=1-0.3$, yielding an effective tax of 30 percent.

The government issues public debt to satisfy its sequential budget constraint.

\section{Calibration: Functional Forms}

Households' preferences are assumed to take the form 
Table 1

Calibration Targets and Parameter Values

\begin{tabular}{lccccc} 
Empirical targets & A/Y & IES & Average hours & $\begin{array}{c}\text { Contribution of labor } \\
\text { income/output }\end{array}$ & $\begin{array}{c}\text { Investment } \\
\text { production }\end{array}$ \\
\hline Empirical values & 3.5 & 0.5 & $1 / 3$ & 0.7 & 0.12 \\
Parameters & $\beta$ & $\sigma$ & $\gamma$ & $\alpha$ & $\delta$ \\
Calibrated values & 1.003 & 4 & 0.327 & 0.3 & 0.0437 \\
\hline
\end{tabular}

(6)

$$
\sum_{i=1}^{I} \beta^{i-1} \frac{\left(c_{i}^{\gamma}\left(1-l_{i}\right)^{1-\gamma}\right)^{1-\sigma}}{1-\sigma}
$$

where $\beta>0$ represents the discount rate, $\gamma \in(0,1)$ denotes the share of consumption in the utility function, and $\sigma>0$ governs the concavity of the utility function. The implied intertemporal elasticity of substitution of consumption (IES) is equal to $1 /(1-(1-\sigma) \gamma)$.

Technology has constant returns to scale and takes the standard Cobb-Douglas form $Y_{t}=K_{t}^{\alpha} L_{t}^{1-\alpha}$, where $\alpha$ represents the capital-income share.

\section{Calibration: Empirical Targets}

We define aggregate capital to be the level of fixed sssets in the Bureau of Economic Analysis statistics. Therefore, our calibration target will be a ratio $K / Y=3$ in yearly terms. Also, computing the ratio of outstanding (federal, state, and local) government debt to gross domestic product (GDP), we get the following ratio $B / Y=0.5$ in yearly terms. Depreciation is also taken from the data, which as a fraction of GDP is 12 percent. Another calibration target is an average of one-third of the time of households allocated to market activities. We choose a curvature parameter in the utility function consistent with a coefficient of relative risk aversion in consumption of 2 (alternatively a consumption intertemporal elasticity of substitution of 0.5). Government consumption will be fixed at 18.6 percent of output as in the data. Finally, the capital-income share is taken to be equal to 0.3, as measured in Gollin (2002).

\section{Calibration Results}

To calibrate our economy, we proceed as follows. First, we fix the curvature parameter in the utility function to be $\sigma=4$ and the capital share in the production function $\alpha=0.3$. Then the discount factor $\beta=1.003$ is chosen to match a wealth-to-output ratio of $3.5,{ }^{5}$ and the consumption share $\gamma=0.327$ is chosen to match an average of one-third of the time devoted to working in the market economy. The depreciation rate is chosen so that in equilibrium depreciation is 12 percent of output. Notice that $\sigma=4$ and $\gamma=0.327$ together imply a consumption intertemporal elasticity of substitution of 0.5 (constant relative risk aversion of 2). Table 1 summarizes the parameters chosen and the empirical targets that are more related to them.

Using the empirical tax rates and ratio of government consumption to GDP, we derive from the government budget constraint an implied equilibrium government debt of 50 percent of output. This figure is consistent with the average figure in the data. Therefore, the capital-to-output ratio is 3 as desired.

Given this parameterization, Social Security annual payments in the benchmark economy amount to 7.35 percent of GDP and the Social Security implicit debt is equal to 128 percent of annual GDP.

\section{THE GOVERNMENT PROBLEM: THE PRIMAL APPROACH}

We use the primal approach of optimal taxation as first proposed by Atkinson and Stiglitz (1980). This approach is based on characterizing the set of allocations that the government can

\footnotetext{
5 Notice that in a finite-life framework there is no problem with discount factors larger than 1, and, in fact, empirical estimates often take values as large.
} 
implement with the given policy instruments available. A benevolent fiscal authority chooses the optimal tax burden, taking into account the decision rules of all individuals in the economy and the effect of their decisions on market prices.

Therefore, the government problem amounts to maximizing the social welfare function over the set of implementable allocations together with the status quo constraints (that guarentee Pareto improvements). ${ }^{6}$ From the optimal allocations, we can decentralize the economy, finding the prices and the tax policy associated with the optimal policy.

A key ingredient is the derivation of the set of implementable allocations. Effectively, it amounts to using the consumer's Euler condition and laborsupply condition to express equilibrium prices as functions of individual allocations and then substituting these prices in the consumer's intertemporal budget constraint. Any allocation satisfying the implementability condition by construction satisfies the household's first-order optimality conditions, with prices and policies appropriately defined from the allocation. See Chari and Kehoe (1999) for a description of this approach.

To illustrate this procedure, we derive the implementability constraint for a newborn individual. Notice that in our case the fiscal authority has to consider retirement pensions as given and that this is going to introduce a difference with Erosa and Gervais (2002), Garriga (1999), or Conesa and Garriga (2008).

We distinguish two cases: first, retirement pensions are considered as regular labor income and are treated as such from a fiscal point of view; and second, retirement pensions are not subject to taxation. Both cases have different tax policy implications.

\section{RETIREMENT PENSIONS AS TAXABLE LABOR INCOME}

For clarity of exposition, we suppress the time subscripts. Consider the household maximization

6 Throughout the paper, we assume that the government can commit to its policies. This is an important restriction that affects the results. The analysis of a time-consistent reform goes beyond the scope of this paper. problem for a newborn individual facing equilibrium prices and individual specific tax rates on consumption, labor income, and capital income:

$$
\begin{aligned}
& \max \sum_{i=1}^{I} \beta^{i-1} u\left(c_{i}, l_{i}\right) \\
& \text { s.t. }\left(1+\tau_{i}^{c}\right) c_{i}+a_{i+1} \leq\left(1-\tau_{i}^{l}\right) w \varepsilon_{i} l_{i}+\left(1+\left(1-\tau_{i}^{k}\right) r\right) a_{i}, \\
& i=1, \ldots, i_{r}-1 \\
& \left(1+\tau_{i}^{c}\right) c_{i}+a_{i+1} \leq\left(1-\tau_{i}^{l}\right)\left(w \varepsilon_{i} l_{i}+p\right)+\left(1+\left(1-\tau_{i}^{k}\right) r\right) a_{i}, \\
& \quad i=i_{r}, \ldots, I \\
& a_{1}=0, a_{I+1}=0, c_{i} \geq 0, l_{i} \in(0,1) .
\end{aligned}
$$

Notice two important features of this formulation. The first one is that individuals of age $i_{r}$ and older have a retirement pension, denoted by $p$, as part of their labor income (and it is taxed at the same rate as regular labor income). Second, on retirement individuals could still supply labor in the market.

Denoting by $v_{i}$ the Lagrange multiplier of the corresponding budget constraint, the necessary and sufficient first-order conditions for an interior optimum are given by

$$
\begin{aligned}
& {\left[c_{i}\right] \quad \beta^{i-1} u_{c_{i}}=v_{i}\left(1+\tau_{i}^{c}\right),} \\
& {\left[l_{i}\right] \quad \beta^{i-1} u_{l_{i}}=-v_{i}\left(1-\tau_{i}^{l}\right) w \varepsilon_{i}, \text { and }} \\
& {\left[a_{i+1}\right] \quad v_{i}=v_{i+1}\left[1+\left(1-\tau_{i}^{k}\right) r\right],}
\end{aligned}
$$

together with the intertemporal budget constraint.

Multiplying these conditions by the corresponding variable we get

$$
\begin{aligned}
& \beta^{i-1} C_{i} u_{C_{i}}=v_{i}\left(1+\tau_{i}^{c}\right) c_{i}, \\
& \beta^{i-1} l_{i} u_{l_{i}}=-v_{i}\left(1-\tau_{i}^{l}\right) w \varepsilon_{i} l_{i}, \text { and } \\
& v_{i} a_{i+1}=v_{i+1}\left[1+\left(1-\tau_{i}^{k}\right) r\right] a_{i+1} .
\end{aligned}
$$

Let $p_{i}=p$ if $i=i_{r}, \ldots, I$, and zero otherwise. Adding equations (10) and (11) over all $i$, 


$$
\begin{aligned}
& \sum_{i=1}^{I} \beta^{i-1}\left[C_{i} u_{C_{i}}+l_{i} u_{l_{i}}\right] \\
& =\sum_{i=1}^{I} \beta^{i-1} v_{i}\left[\left(1+\tau_{i}^{C}\right) c_{i}-\left(1-\tau_{i}^{l}\right) w \varepsilon_{i} l_{i}\right] \\
& =\sum_{i=1}^{I} v_{i}\left(1-\tau_{i}^{l}\right) p_{i},
\end{aligned}
$$

where the second equality comes from using equation (12) and the budget constraints.

Finally, using equation (8) we get

$$
\sum_{i=1}^{I} \beta^{i-1}\left[C_{i} u_{C_{i}}+l_{i} u_{l_{i}}\right]=-\sum_{i=1}^{I} \beta^{i-1} u_{l_{i}} \frac{p_{i}}{w \varepsilon_{i}}
$$

or:

$$
\sum_{i=1}^{I} \beta^{i-1}\left[c_{i} u_{C_{i}}+u_{l_{i}}\left(l_{i}+\frac{p_{i}}{w \varepsilon_{i}}\right)\right]=0,
$$

where $w$ denotes the marginal product of labor.

Any feasible allocation of consumption and leisure satisfying equation (13) can be decentralized as the optimal behavior of a consumer facing distortionary taxes. These distortionary taxes can be constructed by using the consumer's optimality conditions for the labor and leisure and for the consumption and savings margins. In particular, given an allocation and its corresponding prices, constructed from the marginal product of labor and capital, we can back out the optimal tax on capital and labor income by using the Euler and labor-supply conditions:

$$
\begin{gathered}
u_{C_{i}}=\frac{1+\tau_{i}^{C}}{1+\tau_{i+1}^{C}} \beta u_{c_{i+1}}\left[1+\left(1-\tau_{i}^{k}\right) r\right], \text { and } \\
-\frac{u_{l_{i}}}{u_{c_{i}}}=\frac{1-\tau_{i}^{l}}{1+\tau_{i}^{C}} W \varepsilon_{i} .
\end{gathered}
$$

Notice that in this case the optimal policy is not uniquely determined. Labor and consumption taxation are equivalent in the sense that they determine the same distortionary margin. Also, the taxation of capital income is equivalent to taxing consumption at different times at different rates.
In practice, this implies that one of the instruments is redundant. For example, we could set consumption taxes to zero (or to any other constant) and decentralize the allocation using only labor- and capital-income taxes by solving a system of two equations (14) and (15) in two unknowns, $\tau_{i}^{k}$ and $\tau_{i}^{l}$.

Finally, directly using the consumer's budget constraints, we could construct the corresponding sequence of assets. That way we would have constructed an allocation that solves the consumer's maximization problem.

The primal approach of optimal taxation simply requires maximizing a social welfare function over the set of implementable allocations-subject to the feasibility constraint, an implementability condition such as equation (13) for the newborn cohorts, and additional implementability constraints for each cohort alive at the beginning of the reform. We also impose that allocations must provide at least as much utility as in the initial steady state of our economy. The allocation implied by the optimal policy can be decentralized with distortionary taxes in the way we have just outlined.

\section{NONTAXABLE RETIREMENT PENSIONS}

If pensions are not taxable, the maximization problem of the households is given by

$$
\begin{aligned}
& \max \sum_{i=1}^{I} \beta^{i-1} u\left(c_{i}, l_{i}\right) \\
& \text { s.t. }\left(1+\tau_{i}^{c}\right) c_{i}+a_{i+1} \leq\left(1-\tau_{i}^{l}\right) w \varepsilon_{i} l_{i}+\left(1+\left(1-\tau_{i}^{k}\right) r\right) a_{i}, \\
& i=1, \ldots, i_{r}-1 \\
& \left(1+\tau_{i}^{c}\right) c_{i}+a_{i+1} \leq\left(1-\tau_{i}^{l}\right) w \varepsilon_{i} l_{i}+p+\left(1+\left(1-\tau_{i}^{k}\right) r\right) a_{i}, \\
& i=i_{r}, \ldots, I \\
& a_{1}=0, a_{I+1}=0, c_{i} \geq 0, l_{i} \in(0,1) .
\end{aligned}
$$

Consequently, through the same procedure used as before we can obtain the expression 


$$
\begin{aligned}
& \sum_{i=1}^{I} \beta^{i-1}\left[c_{i} u_{C_{i}}+l_{i} u_{l_{i}}\right] \\
& =\sum_{i=1}^{I} \beta^{i-1} v_{i}\left[\left(1+\tau_{i}^{C}\right) c_{i}-\left(1-\tau_{i}^{I}\right) w \varepsilon_{i} l_{i}\right] \\
& =\sum_{i=1}^{I} v_{i} p_{i} .
\end{aligned}
$$

Substituting for the Lagrange multiplier, we get

$$
\sum_{i=1}^{I} \beta^{i-1}\left[u_{C_{i}}\left(C_{i}-\frac{p_{i}}{1+\tau_{i}^{C}}\right)+l_{i} u_{l_{i}}\right]=0 .
$$

Notice that in this case the implementability constraint does include a tax term in it, $\tau_{i}^{c}$. This did not happen before in expression (13). Hence, it is always possible to choose a particular taxation of consumption such that the implementability constraint is always satisfied. The reason is that now the fiscal authority could tax consumption at a high level but still compensate the consumer through other taxes. In the previous case, this strategy was not available since it was impossible to tax away the retirement pensions and compensate the consumers without introducing additional distortions in the system.

Another way to illustrate this simple intuition is by simply looking at the intertemporal budget constraint of the household:

$$
\sum_{i=1}^{I} \frac{\left(1+\tau_{i}^{C}\right) c_{i}}{R_{i}}=\sum_{i=1}^{I} \frac{\left(1-\tau_{i}^{l}\right) w \varepsilon_{i} l_{i}}{R_{i}}+\sum_{i=1}^{I} \frac{p_{i}}{R_{i}},
$$

where $R_{1}=1, R_{i}=\prod_{s=2}^{i}\left[1+\left(1-\tau_{s}^{k}\right) r_{s}\right]$.

Let $\tau_{i}^{C}=\tau^{C}$. We impose the same taxation of consumption at each point in time of the lifetime of an individual. Then we could rewrite equation (17) as

$$
\sum_{i=1}^{I} \frac{C_{i}}{R_{i}}=\sum_{i=1}^{I} \frac{1-\tau_{i}^{l}}{1+\tau^{C}} \frac{w \varepsilon_{i} l_{i}}{R_{i}}+\frac{1}{1+\tau^{C}} \sum_{i=1}^{I} \frac{p_{i}}{R_{i}} .
$$

Clearly, one could choose any desired level of taxation of $\tau^{c}$ and still introduce no distortion in the consumption-leisure margin by choosing $\tau_{i}^{l}=\tau^{l}=\tau^{c}$. Effectively, $\tau^{c}$ would act as a lump sum tax.

Therefore, under this new scenario the planner could decentralize a first-best allocation by strategically setting consumption taxes to replicate lump sum taxation.

Notice that this strategy cannot be replicated for the case when retirement pensions are taxable as regular labor income, since the equivalent of equation (17) would be

$$
\sum_{i=1}^{I} \frac{C_{i}}{R_{i}}=\sum_{i=1}^{I} \frac{1-\tau_{i}^{l}}{1+\tau^{C}} \frac{w \varepsilon_{i} l_{i}}{R_{i}}+\sum_{i=1}^{I} \frac{1-\tau_{i}^{l}}{1+\tau^{C}} \frac{p_{i}}{R_{i}}
$$

and hence the fiscal authority is forced to introduce a distortionary wedge in the consumptionleisure margin when trying to implement lump sum taxation as before.

We are interested in distortionary tax responses to demographic shocks. Consequently, we focus on the scenario where the fiscal treatment of retirement pensions has to be the same as the one of regular labor income. However, we compare the outcomes, in terms of welfare, with the ones that could be obtained if the government could implement lump sum taxation.

\section{THE RAMSEY PROBLEM}

We assume that in period $t=1$ the economy is in a steady state with a PAYG Social Security system and that no demographic shock or government intervention has been anticipated by any of the agents in the economy. The expected utility for each cohort remaining in the benchmark economy is given by

$$
\bar{U}_{j}=\sum_{s=j}^{I} \beta^{s-j} u\left(\hat{c}_{s}, 1-\hat{l}_{s}\right),
$$

where $\hat{c}_{s}, \hat{l}_{s}$ are steady-state allocations of cohort $s$. At the beginning of period 2, the demographic shock is known, and then in response to it the optimal policy from then on is announced and implemented. We require that the fiscal authority guarantees to everybody at least the level of utility of the benchmark economy so that the resulting 


\section{Conesa and Garriga}

policy reform constitutes a Pareto improvement. This participation constraint will ensure that the optimal response to a demographic shock generates no welfare losses (neither for the initially alive nor the unborn).

Notice that we are imposing a very strong participation constraint, since we require that nobody is worse off relative to a benchmark in which actual fiscal policies would have been sustainable forever (i.e., the initial steady state). Alternatively, we could have postulated different arbitrary policy responses to the demographic shock generating welfare losses for some generations and then improved on those. Clearly, our specification imposes stronger welfare requirements and is independent of any arbitrary nonoptimal policy we might have chosen instead. Besides, the main conclusion in the literature is that no matter what policy you choose, somebody will have to pay the cost of the demographic shock. We show this is not necessarily the case.

The government objective function is a utilitarian welfare function of all future newborn individuals, where the relative weight that the government places on present and future generations is captured by the geometric discount factor $\lambda \in(0,1)$, and $U\left(c^{t}, l^{t}\right)$ represents the lifetime utility of a generation born in period $t$.

Conditional on our choice of weights placed on different generations, ${ }^{7}$ the Ramsey allocation is the one that solves the following maximization problem:

$$
\begin{aligned}
& \max \sum_{t=2}^{\infty} \lambda^{t-2} U\left(c^{t}, I^{t}\right), \\
& \text { s.t. } \sum_{i=1}^{I} \mu_{i, t} c_{i, t}+K_{t+1}-(1-\delta) K_{t} \\
& +G_{t} \leq F\left(K_{t}, \sum_{i=1}^{I} \mu_{i, t} \varepsilon_{i} I_{i, t}\right) t \geq 2,
\end{aligned}
$$

7 We are identifying one Pareto-improving reform, but it is not unique. Placing different weights on generations or the initial old would generate a different distribution of welfare gains across agents.
(20) $\sum_{i=1}^{I} \beta^{i-1}\left[\begin{array}{l}c_{i, t+i-1} u_{c_{i, t+i-1}} \\ +u_{l_{i, t+i-1}}\left(l_{i, t+i-1}+\frac{p_{i}}{F_{2, t+i-1} \varepsilon_{i}}\right)\end{array}\right]=0 \quad t \geq 2$,

(21)

$$
\begin{aligned}
& \sum_{s=i}^{I} \beta^{s-i}\left[C_{s, s-i+2} u_{C_{s, s-i+2}}+u_{l_{s, s-i+2}}\left(l_{s, s-i+2}+\frac{p_{i}}{F_{2, s-i-2} \varepsilon_{i}}\right)\right] \\
& =\frac{u_{c_{i, 2}}}{1+\tau_{2}^{c}}\left[\left(1+\left(1-\tau^{k}\right) r_{2}\right) \bar{a}_{i, 2}+p_{i}\right], \quad i=2, \ldots, I
\end{aligned}
$$

$$
\sum_{s=i}^{I} \beta^{s-i} u\left(c_{s, s-i+2}, 1-l_{s, s-i+2}\right) \geq \bar{U}_{i}, \quad i=2, \ldots, I
$$

and

$$
U\left(c^{t}, I^{t}\right) \geq \bar{U}_{1}, t \geq 2 .
$$

Constraint (19) is the standard period resource constraint. Constraint (20) is the implementability constraint for each generation born after the reform is implemented and is exactly the one derived in equation (13). This equation reveals that the government faces a trade-off when determining the optimal labor-income tax of the older generations. A higher labor-income tax is an effective lump sum tax on Social Security transfers, but it also reduces the incentives of the older generations to supply labor in the market. The optimal policy will have to balance these opposite forces. Constraint (21) represents the implementability constraints for those generations alive at the beginning of the reform, where $\tau^{k}$ is the benchmark tax on capital income, which is taken as given and $\bar{a}_{i, 2}$ are the initial asset holdings of generation $i$. Notice that taking $\tau^{k}$ as given is not an innocuous assumption, since that way we avoid confiscatory taxation of the initial wealth. Finally, constraints (22) and (23) guarantee that the policy chosen makes everybody at least as well off as in the benchmark economy. In particular, given that the government objective function does not include the initial $s$ generations, equation (22) will be binding.

This formulation imposes some restrictions, since it rules out steady-state golden-rule equilibria. Also, the initial generations alive at the beginning of the reform are not part of the objective function and appear only as a policy constraint. 
An equivalent formulation would include the initial $s$ generations in the objective function with a specific weight $\lambda_{s}$, where the weight is chosen to guarantee that the status quo conditions for each generation are satisfied.

The policymaker discounts the future at the exponential rate $\lambda$. The Pareto-improving nature of the reform implies that the rate $\lambda$ has to be big enough to satisfy the participation constraints of all future generations. In particular, if $\lambda$ were too low, then the long-run capital stock would be too low, and future generations would be worse off than in the benchmark economy. That restricts the range of admissible values for $\lambda$.

Within a certain range, there is some discretion in the choice of this parameter, implying a different allocation of welfare gains across future generations. To impose some discipline, we choose $\lambda$ so that the level of debt in the final steady state is equal to that of the benchmark economy and all debt issued along the transition is fully paid back before reaching the new steady state. Our choice of the planner's discount factor, the parameter $\lambda=0.957$, implies the full repayment of the level of debt issued in response to the demographic shock. That does not mean that the ratio of debt to output will be the same in the final steady state, since output does change.

\section{FURTHER CONSTRAINTS IN THE SET OF TAX INSTRUMENTS}

We impose additional restrictions in the set of fiscal instruments available to the fiscal authority. This can be done by using the consumer's firstorder conditions in order to rewrite fiscal instruments in terms of allocations and then imposing additional constraints on the Ramsey allocations.

The regime we investigate is one in which capital-income taxes are left unchanged relative to the benchmark. Reformulating this constraint in terms of allocations, we need to impose

$$
\begin{aligned}
& \frac{u_{c_{1, t}}}{u_{C_{2, t+1}}}=\frac{u_{C_{2, t}}}{u_{C_{3, t+1}}}=\ldots=\frac{u_{C_{I-1, t}}}{u_{C_{I, t+1}}} \\
& =\beta\left[1+\left(1-\tau^{k}\right)\left(f_{k, t+1}-\delta\right)\right], t \geq 2 .
\end{aligned}
$$

We introduce this constraint since we want to analyze an environment in which the reforms involve only changing the nature of labor-income taxation so that welfare gains are accrued only because of the change in the nature of the financing of retirement pensions rather than a more comprehensive reform involving also changes in the nature of capital-income taxation. Moreover, as Conesa and Garriga (2008) show, the additional welfare gain of reforming capital-income taxation is very small.

With such a constraint, the only instruments available to the fiscal authority will be the taxation of labor income and government debt.

\section{A TRANSITORY DEMOGRAPHIC SHOCK}

In our experiment, we introduce an unexpected transitory demographic shock, capturing the idea that an increase in the dependency ratio is going to break down the sustainability of the Social Security system we had in the initial steady state of our benchmark economy.

The reason that we want to model it as an unexpected shock is that we want to investigate the optimal response from now on, instead of focusing on what we should have done in advance of an expected shock.

Since introducing realistic demographic projections would imply having to change substantially the demographic structure of our framework, we choose a very simple strategy. We simply increase the measure of retiring individuals for three consecutive periods. Notice that the demographic shock is transitory, in the sense that for three periods (equivalent to 15 years) we face raising dependency ratios, and then for another three periods the dependency ratio falls until reaching its original level and staying there forever. We chose this specification of the demographic shock for computational convenience, since otherwise the model would imply changes in the age structure over time. The alternative would have been an environment where at some point the final age permanently increases reflecting an increase in life expectancy. This raises some com- 


\section{Figure 3}

\section{Evolution of the Dependency Ratio for Simulated Demographic Shock}

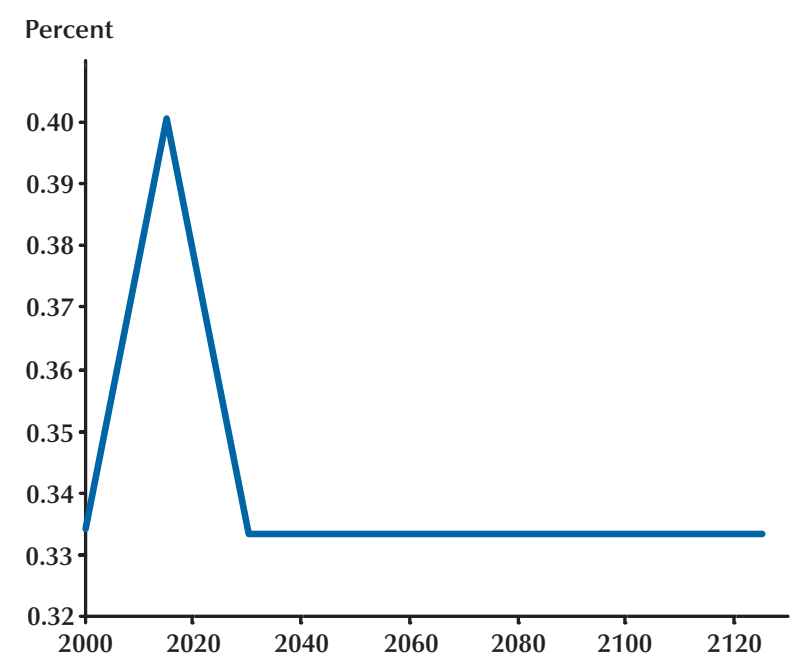

putational problems, especially if individuals could forecast the demographic evolution and form expectations about future paths of government action. Hence, the benchmark economy would not be a steady state anymore, and the state of the economy at the benchmark date would be fully driven by arbitrarily chosen expectations. Figure 3 illustrates the evolution of the dependency ratio over time.

We have arbitrarily chosen to label the initial steady state in period 1 as the year 2000, and the demographic shock will be observed and fully predictable at the beginning of period 2 (the year 2005). Hence, the results that follow imply that the policy response from 2005 on is publicly announced and implemented at the beginning of 2005.

Notice that both individuals and the government are assumed to be surprised by the demographic shock. The government learns that given the demographic evolution the system is not sustainable and then implements a policy that rationalizes the financing of pensions. Not only will the government optimally respond to the demographic shock guaranteeing the financial sustainability of pensions in a Pareto-improving way, but moreover the government will permanently change the financing scheme of pensions, hence generating long-run welfare gains relative to the benchmark economy. Our exercise is silent about the reasons why any collective decision process would have resulted in such a distortionary financing scheme in the first place. Indeed, the demographic shock in our exercise triggers the government response, but there is no clear reason why the government should not reform the system in the first place even in the absence of a demographic shock, purely for efficiency considerations. This is exactly what Conesa and Garriga (2008) do in an environment where the government is not constrained to guarantee the pensions promised in the past.

\section{DISCUSSION OF RESULTS}

The optimal reform is obtained by solving the maximization problem as stated in the previous section, with the only difference that we have introduced equation (24) as an additional constraint.

We find that the optimal financing scheme implies differential labor-income taxation across age. Why would the government choose to tax discriminate? The critical insight is that when individuals exhibit life-cycle behavior, labor productivity changes with the household's age and the level of wealth also depends on age. As a result the response of consumption, labor, and savings decisions to tax incentives varies with age as well. On the one hand, older cohorts are less likely to substitute consumption for savings as their remaining life span shortens. On the other hand, older households are more likely to respond negatively to an increasing labor-income tax than younger cohorts born with no assets, since the elasticity of labor supply is increasing in wealth. Therefore, the optimal fiscal policy implies that the government finds it optimal to target these differential behavioral elasticities through tax discrimination.

Figure 4 describes the evolution of the average optimal taxes along the reform. We decentralize the resulting allocation leaving consumption taxes unchanged, even though it is possible to decentral- 


\section{Figure 4}

\section{Evolution of Average Taxes}

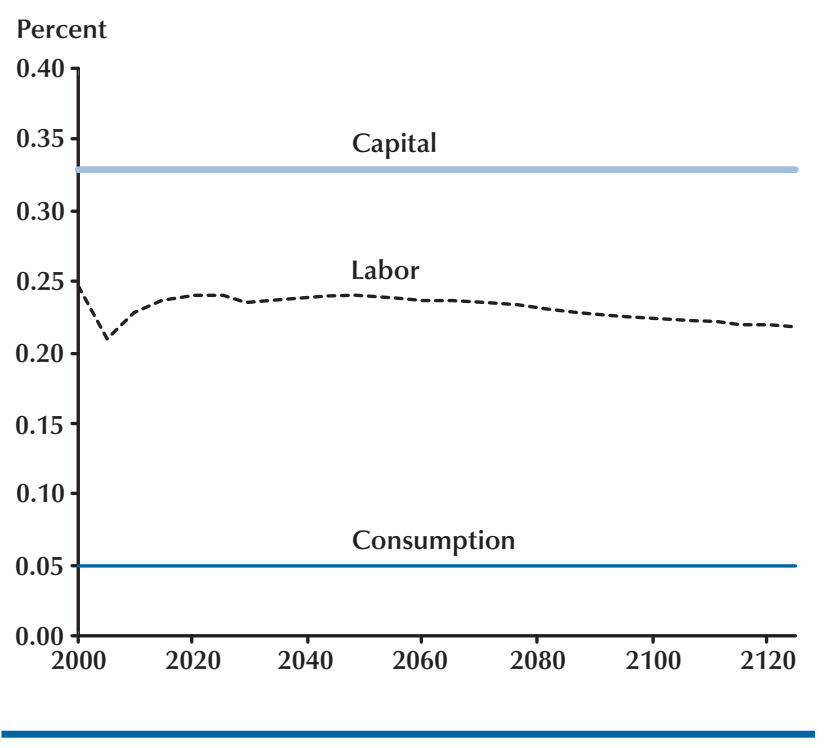

ize the same allocation in alternative ways. In particular, we could set consumption taxes to zero and increase labor-income taxes so that they are consistent with the optimal wedge chosen by the government.

In displaying the results, we arbitrarily label the year 2000 to be the steady state of the benchmark economy, and the reform is announced and implemented the following period (in 2005). Remember that a period in the model is 5 years.

Labor-income taxes are substantially lowered the first period following the reform (the combined impact of labor-income and payroll taxes was a 24.8 percent effective tax on labor in the benchmark), but then they are increased to repay the initial debt issued and reach a new long-run equilibrium around 22 percent on average.

Figure 5 displays its distribution across age at different points in time. The optimal laborincome tax rate varies substantially across cohorts. In the final steady state, the optimal labor-income tax schedule is concave and increasing as a function of age, up to the point at which individuals start receiving a pension. On retirement, the taxation of labor income (remember that retirement pensions are taxed at the same rate as regular

\section{Figure 5}

\section{Labor-Income Tax Rates Across Different Cohorts at Different Times}

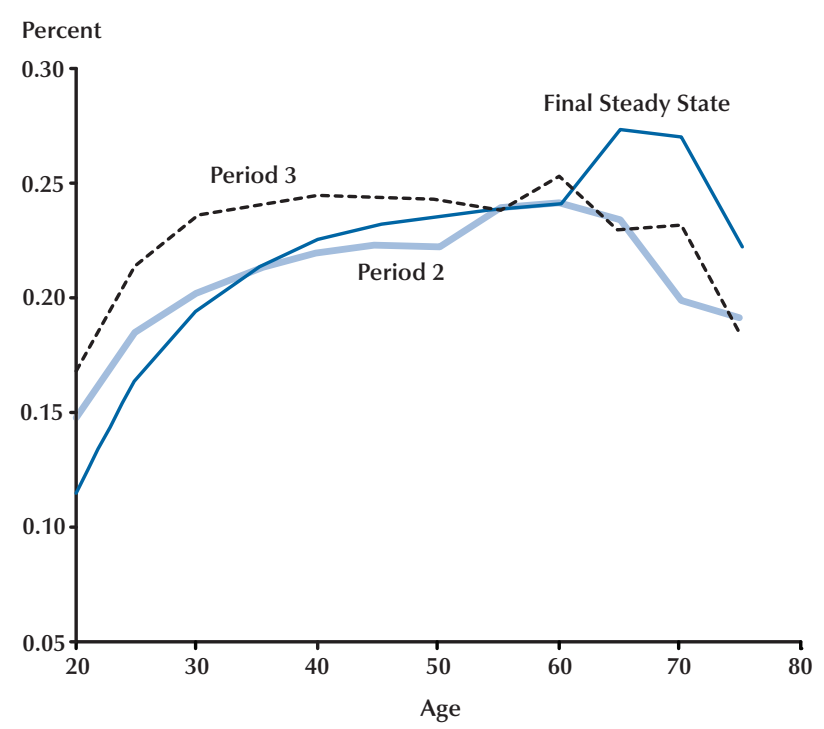

labor income) is higher. This feature reflects the tension between the incentives for the fiscal authority to tax away the retirement pensions and the distortions that introduces on labor supply.

Intuitively, the fiscal authority introduces such labor-income tax progressivity to undo the intergenerational redistribution in favor of the older cohorts that the Social Security system is generating.

As a result of this new structure of laborincome taxation, individuals will provide very little labor supply after age 65 and almost none in the last period, as shown in Figure 6. Notice that the shape of labor supply is not dramatically changed with the reform, except for the fact that individuals would still provide some labor while receiving a retirement pension. However, the amount of labor supplied by the oldest cohorts is quite small.

The initial tax cuts, together with the increasing financial needs to finance the retirement pensions, necessarily imply that government debt has to increase in the initial periods following the reform. 


\section{Figure 6}

\section{Labor Supply Across Different Cohorts at Different Times}

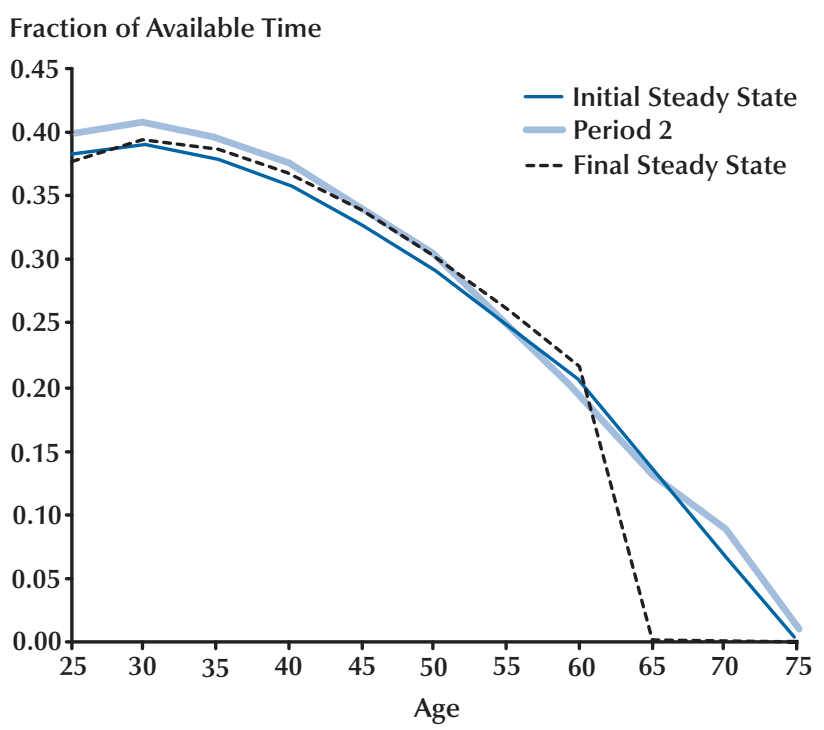

\section{Figure 8}

\section{Welfare Gains of Newborn Generations}

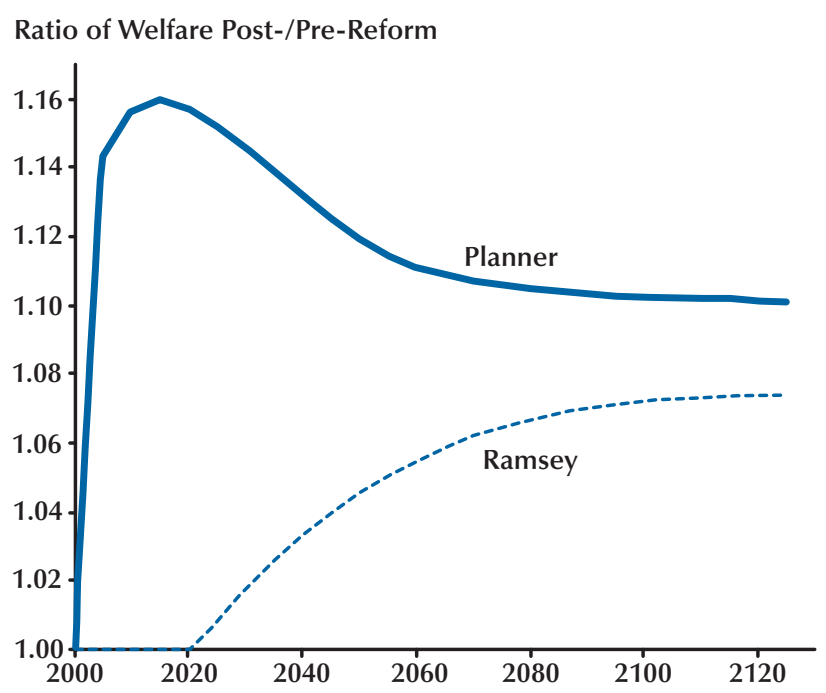

\section{Figure 7}

\section{Evolution of Debt-to-GDP Ratio}

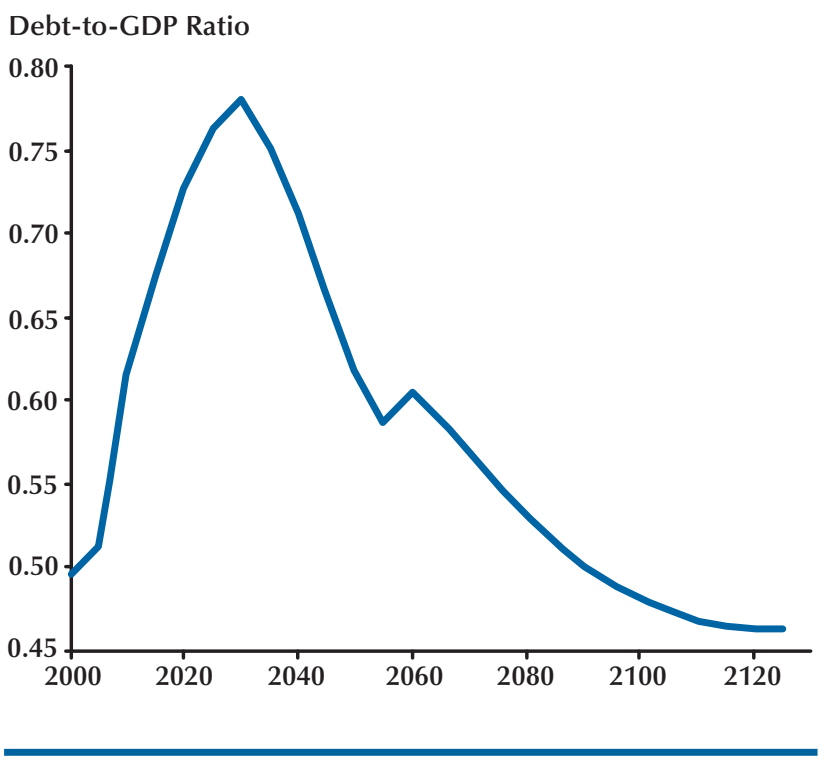

Next, Figure 7 displays the evolution of government debt over GDP associated with the optimal reform. To finance retirement pensions, government debt would increase up to 77 percent of annual GDP (relative to its initial 50 percent). Later on, this debt will be progressively repaid.

Overall, such a reform generates welfare gains only for those cohorts born once the demographic shock is over. However, the optimal response guarantees that the cohorts initially alive and those born during the shock enjoy the same level of utility as in the benchmark economy. Notice that by construction the initial old were not included in the objective function, and as a consequence the constraint to achieve at least the same utility level as in the benchmark economy has to be necessarily binding. This was not the case for new generations born during the demographic shock since they were included in the objective function of the fiscal authority. Yet the optimal policy response implies that the constraint will be binding, and only after the demographic shock is over will newborn cohorts start enjoying higher welfare. The welfare gains accruing to newborns are plotted in Figure 8. 
The optimal response associated with the sustainable policy contrasts with the findings where policies are exogenously specified as in De Nardi, Imrohoroglu, and Sargent (1999), where the initial cohorts are worse off, and Jeske (2003), where the baby boomers and the grandchildren of the baby boomers suffer welfare losses. In our economy, the cost of the shock is distributed over the cohorts initially alive and those generations born during the shock. Remember that the latter do enter the government's objective function, and hence the planner would be happy to allocate some welfare gains to these generations if it were possible. ${ }^{8}$

Notice that the welfare gains associated with the reform just discussed, labeled as "Ramsey" in Figure 8, are much smaller than those associated with the first-best allocation, labeled as "Planner."

By construction, we have prevented the fiscal authority from lump sum taxing the retirement pensions. If we were to allow the fiscal authority to tax differently retirement pensions from regular labor income, the fiscal authority would choose to do so imposing on pensions taxes higher than 100 percent, effectively replicating a system with lump sum taxes. Notice that the welfare gains from doing so (labeled as "Planner") would be much higher, especially for the initial generations. This comparison indicates that the welfare costs of having to use distortionary taxation are very high, especially at the initial periods of the reform.

\section{CONCLUSION}

In this paper, we have provided an answer to a very simple and policy-relevant question: What should be the optimal response to an unanticipated transitory demographic shock in Social Security financing? To answer this question, we use optimal fiscal policy to determine the optimal way to finance some promised level of retirement pensions through distortionary taxation. In our experiment, the presence of a demographic shock

8 This result shows how large the pressure induced by the demographic shock is. This is especially important since our demographic shock is much less severe than expected even under the most optimistic scenario (compare Figures 1 and 3) and the level of distortions present in our benchmark economy is very high. Hence, our exercise is biased toward generating large welfare gains. renders the actual way of financing the Social Security system unsustainable, and our approach endogenously determines how to accommodate this shock, at the same time that the pension financing scheme is permanently changed to reduce distortions.

We find that the government can design a Pareto-improving reform that exhibits sizeable welfare gains in the distant future, after the demographic shock is over. This shows that the pressure induced by the demographic shock is substantial, since the reduction of the existing large distortions only prevents welfare losses but does not generate welfare gains until further away in the future. Our approach explicitly provides quantitative policy prescriptions toward the policy design of future and maybe unavoidable Social Security reforms.

The optimal response consists of the elimination of compulsory retirement, decreasing laborincome taxation of the young, and a temporary increase of government debt to accommodate the higher financial needs generated by the increase in the dependency ratio.

\section{REFERENCES}

Atkinson, Anthony B. and Stiglitz, Joseph E. Lectures in Public Economics. New York: McGraw-Hill, 1980.

Boldrin, Michele and Montes, Ana. "The Intergenerational State: Education and Pensions.” Review of Economic Studies, July 2005, 72(3), pp. 651-64.

Boldrin, Michele and Rustichini, Aldo. "Political Equilibria with Social Security." Review of Economic Dynamics, January 2000, 3(1), pp. 41-78.

Chari, V. V. and Kehoe, Patrick J. "Optimal Fiscal and Monetary Policy,” in John B. Taylor and Michael C. Woodford, eds., Handbook of Macroeconomics. Volume 1C. Amsterdam: Elsevier, 1999, pp. 1671745 .

Conesa, Juan Carlos and Garriga, Carlos. "Optimal Fiscal Policy in the Design of Social Security Reforms." International Economic Review, February 2008, 49(1), pp. 291-318. 


\section{Conesa and Garriga}

Cooley, Thomas F. and Soares, Jorge. "A Positive Theory of Social Security Based on Reputation." Journal of Political Economy, February 1999, 107(1), pp. 135-60.

De Nardi, Mariachristina; Imrohoroglu, Selahattin and Sargent, Thomas J. "Projected U.S. Demographics and Social Security." Review of Economic Dynamics, July 1999, 2(3), pp. 576-615.

Diamond, P. A. "National Debt in a Neoclassical Growth Model." American Economic Review, 1965, 55(5), pp. 1126-50.

Erosa, Andrés and Gervais, Martin. "Optimal Taxation in Life-Cycle Economies." Journal of Economic Theory, August 2002, 105(2), pp. 338-69.

Escolano, Julio. "Optimal Taxation in OverlappingGenerations Models.” Unpublished manuscript, University of Minnesota, 1992.

Feldstein, Martin and Liebman, Jeffrey B. "Social Security," in Alan J. Auerbach and Martin Feldstein, eds., Handbook of Public Economics. Volume 4. Amsterdam: Elsevier, pp. 2245-324.

Gale, David. "Pure Exchange Equilibrium of Dynamic Economic Models." Journal of Economic Theory, February 1973, 6(1), pp. 12-36.
Garriga, Carlos. "Optimal Fiscal Policy in Overlapping Generations Models.” Unpublished manuscript, University of Barcelona, 1999.

Gollin, Douglas. "Getting Income Shares Right." Journal of Political Economy, April 2002, 110(2), pp. 458-74.

Grossman, Gene M. and Helpman, Elhanan. "Integenerational Redistribution with Short-Lived Governments." Economic Journal, September 1998, 108(450), pp. 1299-329.

Hansen, Gary D. "The Cyclical and Secular Behaviour of the Labour Input: Comparing Efficiency Units and Hours Worked." Journal of Applied Econometrics, January-March 1993, 8(1), pp. 71-80.

Jeske, Karsten. (2003), "Pension Systems and Aggregate Shocks.” Federal Reserve Bank of Atlanta Economic Review, First Quarter 2003, 88(1), pp. 15-31; www.frbatlanta.org/filelegacydocs/ erq103_jeske.pdf.

Mendoza, Enrique G.; Razin, Assaf and Tesar, Linda L. "Effective Tax Rates in Macroeconomics: CrossCountry Estimates of Tax Rates on Factor Incomes and Consumption." Journal of Monetary Economics, December 1994, 34(3), pp. 297-323. 